\title{
Smart technologies for energy consumption management
}

\author{
Katarina Hercegová ${ }^{1, *}$, Tatyana Baranovskaya ${ }^{2}$ and Natalya Efanova ${ }^{2}$ \\ ${ }^{1}$ Prague Business School, Werichova str. 1145/29, 15200 Prague, Czech Republic \\ ${ }^{2}$ Federal State Budgetary Educational Institution of Higher Education "Kuban State Agrarian \\ University named after I. T. Trubilin”, Kalinina str. 13, 350044 Krasnodar, Russian Federation
}

\begin{abstract}
The article aims at classifying and describing smart technologies and solutions that are currently used for energy consumption management. It stresses the positive impact of technology on the environment, with a focus on renewable energy, energy efficiency and climate change. The article analyses the green technologies used in energy generation and storage and contemplates over the Internet of Things (IoT) concept that enabled using super-fast flows of information from the generator to the consumer and back with the purpose of optimizing energy management and impacting the demand-side response of the energy consumers. Also, it describes the future smart energy systems that would combines photovoltaic (PV) panels, storage systems and batteries. In addition, it discusses the importance of peer-to-peer ( $\mathrm{P} 2 \mathrm{P})$ energy and information exchange, virtual power plants and many other novel elements of the future smart grids that would make the transition to the low-carbon economy and electric transport smooth and effective.
\end{abstract}

\section{Introduction}

Smart energy management programs can be used to reduce and control the energy consumption of buildings, reduce electricity bills, while increasing the comfort and productivity of residents, and improve environmental sustainability without affecting living standards $[1,2]$. This includes everything from lighting and other devices to charging stations in car parks, air conditioning, refrigerators and air conditioning.

In order to achieve the goals of energy management, the individual energy use of the appliances must be combined with intelligent operation and control of the appliances. This can be achieved, for example, by a distributed single-point sensor system that equips devices with energy acquisition and measurement, or by a wireless sensor and actuator network (WSAN)-based lighting or any other smart home control system [3,4].

Programmes that promise the best combination of smart devices, smart lighting, smart devices and smart controls are the best to pursue. The smart devices communicate with each other, enabling residents to automatically monitor and control the lighting, security systems and energy consumption of the homes. Smart appliances are household appliances that combine embedded computing, sensor and communication capabilities to enable smart

\footnotetext{
*Corresponding author: hercegova@pbs-education.cz
} 
decision-making. The deployment of accelerates the deployment of smart appliances by facilitating the addition of communication capabilities to household appliances. The sensor capability allows the device to measure energy consumption and report it to its local energy authority, while its actuation capability allows it to respond to orders from it. To this end, building managers and residents alike must define the appropriate energy management strategy $[5,6]$.

Energy-efficient household management requires recommendations and forecasts based on energy consumption patterns. Energy and sensor systems, use the capabilities of smart meters and smart devices can all be integrated into the next generation of smart meters. State Grid and Hunan IES have signed a strategic agreement for integrated energy services, building on the success of Huawei's Smart Internet of Things (IoT) solutions acquired from State Grid of China, China's second largest energy provider. The platform can collect data from over 50 different types of devices, including smart thermostats, air conditioners, refrigerators, heaters and air conditioning systems. It helps companies improve energy efficiency, reduce energy costs, eliminate potential energy and safety risks, ensure green and safe operation and improve corporate governance [7].

Companies can use energy savings to effectively reduce energy consumption in research and production. Energy-efficient energy management systems such as smart meters and smart appliances support the use of energy-efficient appliances, sensors and other technologies to ensure efficient operation. Market analysts predict that investment in industrial energy management will grow faster in manufacturing than in the residential, commercial and construction sectors. These systems come in a variety of forms, including smart thermostats, energy-efficient appliances, smart meters, smart appliances and other technologies [8]. For example, the transportation industry is one of the largest users of smart technology in the United States. Recent studies informed that 493 cities surveyed by the International Association of City and County Administrators used energy-related smart technologies - in 2015, an increase of more than 20 percent from 2014. Sales of IoT devices in cities are expected to triple between 2015 and 2020, and software sales are expected to double [9].

When collecting data from various smart devices that control electricity-consuming systems, facility managers can reduce total energy consumption. By breaking down energy usage into different subsets for measurement, from measurement to undermeasurement, they can look at the energy consumption of different systems separately. Ultimately, the potential is to reduce a system's energy costs by 30 percent simply by analysing the data and adjusting the motors. Organisations and business companies can move faster when they try to discover opportunities for energy efficiency than in the past, especially in terms of energy management. Big tech players also want to have their stake in this process. For example, an intelligent energy management solution from Panasonic is driving a smart city project in Berlin that saves carbon dioxide and supplies $90 \%$ of households with almost $\mathrm{CO}_{2}$-free heating [10].

Overall, technology can help to save us more energy using novel technological solutions such as predictive analytics that measure the energy consumption of commercial buildings, smart meters and various smart devices. Of course, the data analysis from the energy sector that is increasingly becoming the Big Data analysis that requires special skills and forces in terms of manpower and in terms of information and communication solutions that arise every day. The way to achieve energy efficiency in cities is to save energy - to make buildings more efficient and to build new homes and offices that are also energy efficient. 


\section{Technological solution for energy conservation}

This section of the article is dedicated to the positive impact of technology on the environment, with a focus on renewable energy, energy efficiency and climate change. Renewable energy, also known as "clean energy," is energy produced from naturally renewable resources. Modern environmental technology allows us to capture this naturally occurring energy and convert it into electricity and useful heat, reflecting the technology's extremely positive impact on the environment. Renewables generate more than $20 \%$ of Britain's electricity, with wind, solar and geothermal energy sources such as wind turbines and solar panels becoming our second largest generator. For example, European Union targets mean that this share is likely to rise to $30 \%$ by 2020 , and, according to the United Kingdom Department of Energy and Climate Change (DECC), more than half of Britain's electricity will come from renewable sources by 2050, with solar, wind and hydro power becoming the second largest United Kingdom generator [11].

It is clear that the governments and their industry partners worldwide are pinning their hopes on public-private partnerships leading to technological breakthroughs that will enable coal-fired power plants to continue to provide safe and affordable energy. Optimising existing plants is the low-hanging fruit of technology, because it makes the best use of what we already have. In the United States, optimization involves the use of sophisticated software that helps plants reduce emissions, increase efficiency, and improve reliability. The plant has been upgraded to new pollution control facilities to emit carbon dioxide and other emissions, including mercury [12]. Primitive artificial intelligence (AI) and machine learning analyse the icy surface over time - measured changes that help researchers plant plants with the best potential to maximize carbon sequestration, and warning systems that contain destructive algal blooms. Through the use of machine learning and artificial intelligence, AI also has an impact on agricultural practices. In a way, AI is changing the way energy generation and storage are conducted in developed countries, reducing dependence on various factors. Materials scientists are using artificial intelligence to develop biodegradable plastic substitutes, and some are developing strategies to clean up the oceans, which receive eight million tonnes of plastic annually. The United States Department of Energy's National Oceanic and Atmospheric Administration (NOAA) is developing a strategy to clean up the oceans, which produce up to eight million tonnes of plastic annually, as part of its Clean Ocean Initiative [13].

In broad terms, clean energy generally means energy produced from renewable energy sources that emit fewer greenhouse gas emissions than fossil fuels and clean, decentralised generation. Customers worldwide are getting more aware that their products, buildings and houses can be certified independently of each other, that they use less energy to reduce emissions, reduce air pollution and contribute to climate protection. This is a useful information that might help to save energy, save money, and protect the environment.

\section{Modern technologies in energy storage and energy utilization}

Currently, thanks to the rise of the information and communication technologies worldwide and the introduction of the concepts of the Internet of Things (IoT) and Internet of Energy (IoE), modern technologies find a wide use in energy storage and energy utilization. For example, there is a Virtual Power Plant (VPP) which is a cloud-based, decentralised energy source that improves the efficiency and reliability of decentralised energy resources such as wind, solar, geothermal and hydropower [14]. Similarly, the Power by Ammonia (P2A) concept offers a solution whereby stored ammonia can be used as an energy source in the form of a gas-phase fuel [15]. Power by Gas (P2G) are new technologies that can convert 
electricity into gas phase fuels and vice versa. The concept of Power by Ammonia (P2A) and Power by Gas (P2G) concepts for the future of energy storage and energy efficiency.

Of all renewable energy sources, hydropower is one of the most commercially developed and the one with the greatest potential for energy storage and efficiency. By building dams and barriers, large reservoirs can be used to generate a controlled flow of water that drives turbines to generate electricity. This energy source is more reliable than solar or wind power, especially when it is tidal energy rather than electricity, and often allows for the storage of electricity for use when demand peaks. Unlike wind, hydropower can in certain situations not only be a more profitable commercial source of energy, but is also often used to generate electricity in the home, depending on the type of property. Compared to other energy sources, it is also more efficient than wind and solar energy [16, 17].

One of the most common uses of pumped hydropower in the United States is to store electricity for periods of high demand, such as extreme weather events. This storage technology is most commonly coupled with solar power plants and accounts for about onethird of total energy storage capacity in North America. This type of heat storage is being built on a very large scale, which is able to provide considerable thermal storage capacity at a relatively low cost. While larger warehouses lose less heat over time, this concentration is advantageous compared to distributing the same capacity among many smaller stores, especially if larger stratification is permitted [18].

Compressed air storage systems could have the potential to make them a cheaper - more effective - storage option for large volumes of storage. This offers a cost advantage over thermal storage systems such as thermal power plants, but also considerable cost advantages in terms of energy efficiency and reliability. The introduction of thermal energy storage brings several advantages for current and future DHC systems. The thermal energy storage (TES) market will vary considerably depending on the application, application and region, with the potential for significant growth in the coming years [19].

All over the world, the development of electric vehicles breaks the traditional dependence on petrochemicals and potentially changes personal mobility. Therefore, the use of thermal energy storage is an important part of the energy mix for the future of transport. In several countries, including Australia, the United States, China and Japan, TES and other forms of cooling water storage are playing an important role as utilities reduce peak loads and consumers cut their electricity bills. One of the most important drivers and prerequisites for this growth is the resulting competitiveness of energy storage systems over conventional nonstorage solutions [20].

In addition, the use of decentralised energy resources, including wind, solar, geothermal, hydroelectric and other renewable energy sources, is changing the nature of transmission and distribution networks. As more smart energy technologies become available for commercial applications, the different costs of energy storage need to be accurately compared. Although there is a levelled cost factor for energy (LCOE) used to compare the costs of different types of storage (e.g. solar, wind, geothermal, hydroelectric, etc.), this is not a generally applied benchmark for calculating meaningful and comparable costs. There are also some factors we consider to be the most important for calculating the price of electricity and its relative competitiveness compared to conventional non-storage solutions. For example, electricity storage can help to integrate more renewable energy into the electricity grid. It can also help to ensure that generating units are optimally operated and that less efficient generating units are used that would otherwise only be used at peak times [21].

In addition, the additional capacity provided by electricity storage can avoid or delay the need to build new power plants or other large energy storage facilities. The possible negative effects of electricity storage will depend on the type and efficiency of storage technology. It can be used for pumping water, compressing air-energy storage, pumping hydro systems or storing running water. Novel energy conversion, storage and conversion technologies can 
store excess electricity when supply exceeds consumer demand. Photovoltaic systems use batteries, and solar thermal systems require a kind of TES system to store heat at night and on cloudy days. Also, there is hydrogen that is produced, compressed, liquefied, converted back into electrical energy and heat and stored deep-frozen at $252-882$ degrees Celsius. It has storage costs of around 8,100 euros and can be produced with an output of 1,000 kilowatt hours $(\mathrm{kWh})$ per year which makes some researchers wonder whether it can become a better energy option [22].

\section{Smart energy consumption systems}

While conventional energy-saving terminals provide access to a wide range of high-energy appliances in a building and are located throughout the building, they cannot control all the highest-energy appliances, including power, heating, air conditioning, cooling, lighting and power distribution systems. Intelligent energy management system - supported terminals can manage more devices than ever before, reducing energy consumption across any country on any distance. Power consumption and emission reductions can be significantly reduced, which would lead to further savings in energy consumption.

Conventional IoT technologies require complex configurations to enable remote control and management of terminals. IoT technology to use a wide range of high-energy devices such as smart thermostats, air conditioning, lighting and power distribution systems, whereas traditional energy-saving terminals do not. Companies can use this energy by saving terminals to effectively reduce energy consumption for research and production. The system features a wide range of smart thermostats, air conditioning, lighting and power distribution systems that have a variety of energy management functions, such as smart lighting, smart heating and cooling, and smart ventilation and air conditioning. One can rely upon the IoT technology to support the management and control of high-energy devices and systems to ensure efficient operation. The neural network takes into account what it knows about its users' energy consumption and their home environment and uses this information to determine how energy can be managed most effectively. While standard energy management systems can monitor a variety of factors such as temperature, humidity, wind speed and humidity, only a few of them are able to detect the full spectrum of energy consumption and its impact on the environment [23].

Although the "Smart Home" standard is all about comfort and energy management, there are various software that go a step further by automating the management of individual circumstances based on their energy requirements and by responding to the specific needs of each individual and their individual energy consumption [24]. One can take some recommendations and take direct action to maximise the energy efficiency at her or his smart home. The key issue is how to increase energy use and efficiency, both taking account of electricity demand and energy-saving concepts.

Some authors propose the use of energy efficiency as a key component of a smart home energy management system. The technology is often not human but intelligent and innovative, and often provides information on the energy consumption of various household appliances such as thermostats, lighting, appliances and appliances. For example, smart plugs that can detect different household appliances and smart lights [25]. Thence, the term smart grid covers a wide range of interconnected technologies that enter into public use to reduce and better manage electricity consumption. The smart grid system can be designed to monitor and control power consumption, such as smart thermostats, smart lighting and smart devices. Power providers could see it as a way to locate blackouts and other problems so that technicians can be deployed to defuse the problem. Consumers connected intelligently to the grid can contribute to a stable, green grid [26, 27]. 
There are various solutions how the smart grid system, an intelligent electricity grid system for the consumer, can be intelligently integrated into electricity systems. Some smart home solutions such as smart meters already exist, but they are not yet widely used, such as smart thermostats, smart lighting and smart devices. Some of the biggest trends in the smart home sector are already evident today: homeowners produce their own electricity through photovoltaic systems (solar batteries) placed on their roofs. They respond to the price of electricity in the markets by increasing their production when electricity is plentiful and cheap. In smart and interconnected households, these react to prices in the electricity markets and adapt to households' usage patterns in order to save electricity and reduce costs. In the future, intelligent management of buildings and services will ensure that unused electricity is stored and used, so that the power supply can be switched to these devices at any time. Smart home technology also comes into play to ensure that the weather does not decide whether enough electricity is available. When saving electricity, the rules are the device should be turned off completely instead of running it in stand-by mode. There are different scenarios to simulate the operation of appliances in real time in a hybrid energy system and to optimize the operation of household appliances to minimize electricity costs. Resource management techniques allow the algorithm to determine the distribution of energy from different sources based on the load. The algorithm can also be re-evaluated for different energy sources. The tool controls the operation of devices by simulating a central computing unit and a dosing unit, a predefined device connected to elements in the home network. In a few years, the smart grid system will basically become the basis for accessing consumption data from a wide range of devices such as smart meters, smart thermostats and smart lighting. This extensive network will allow for the deployment of smart grids in the future, if things continue as they are now, and the development of new technologies for energy management.

\section{Conclusions}

In essence, smart technologies used in energy management will become the key to repairing the damage we have already done to the planet by figuring out how to sustain our species' energy, food, and water needs in the face of climate change and other environmental challenges. We will be able to save the environment, reduce the effects of global warming, adapt to climate change, clean up polluted areas and take care of our own health.

The examples given above in this article show that science and technology will be better prepared to meet the challenges of the future, not only in terms of energy, but also in terms of the environment. In addition, addressing these challenges will enable us to move towards a more sustainable future, an environmentally friendly future that creates qualified jobs. Green technology is an umbrella term that describes the use of technology to create environmentally friendly products and services. Examples of green technologies include the use of technology and infrastructure to recycle waste, purify water, create clean energy and conserve natural resources.

In general terms, the aim of "green technology" is to protect the environment and even to repair the damage that is being done to it. Green technology is related to cleantech, which specifically refers to the development of products and services that improve operational performance while reducing the use of fossil fuels and other non-renewable energy sources. Green technology can be used in energy-saving processes such as energy efficiency, energy saving and energy storage. Green technology is also being used to create alternative sources of fuel that are more environmentally friendly than fossil fuels. Solar, wind and hydro power plants are examples of green technologies because they are environmentally friendly and do not produce fossil fuel waste. These alternative energy sources would soon be used to run homes, utilities and power plants on a massive scale leading to the true "green revolution" that would foster decarbonization and tackle the climate change. 


\section{References}

1. A. Bhati, M. Hansen, C. M. Chan, Energy conservation through smart homes in a smart city: A lesson for Singapore households, Energy Policy, 104, 230-239 (2017)

2. W. Strielkowski, T. Veinbender, M. Tvaronavičienė, N. Lace, Economic ResearchEkonomska Istraživanja, 33 (1), 788-803 (2020)

3. Z, Zhao, W. Lee, Y. Shin, K. Song, IEEE transactions on smart grid, 4 (3), 1391-1400 (2013)

4. W. Strielkowski, Economics \& Sociology, 10 (1), 310-318 (2017)

5. I. Machorro-Cano, G. Alor-Hernández, M. Paredes-Valverde, I. Rodríguez-Mazahua, J. Sánchez-Cervantes, J. Olmedo-Aguirre, Energies, 13 (5), 1097 (2020)

6. G. Rausser, W. Strielkowski, D. Štreimikienè, Energy \& Environment, 29 (1), 131-146 (2018)

7. H. Wang, H. Ma, X. Liu, J. Yang, H. He, Z. Meng, IOP Conference Series: Earth and Environmental Science, 621 (1), 012046 (2021)

8. M. ALiero, K. Qureshi, M. Pasha, G. Jeon, Environmental Technology \& Innovation, 101443 (2021)

9. J. Oh, Sustainability, 12(17), 6874 (2020)

10. Panasonic (2020). Access mode: https://news.panasonic.com/global/topics/2020/79631.html

11. D. Newbery, M. Pollitt, R. Ritz, W. Strielkowski, Renewable and Sustainable Energy Reviews, 91, 695-707 (2018)

12. N. Ryan, J. Johnson, G. Keoleian, G. Lewis, Journal of Industrial Ecology, 22 (6), 1318 1330 (2018)

13. A. Iverson, Conservation Science and Practice, 1 (6), e45 (2019)

14. S. Ali, B. Choi, Electronics, 9 (6), 1030 (2020)

15. A. Valera-Medina, H. Xiao, M. Owen-Jones, W. David, P. Bowen, Progress in Energy and combustion science, 69, 63-102 (2018)

16. X. Luo, J. Wang, M. Dooner, J. Clarke, Applied Energy, 137, 511-536 (2015)

17. M. Simionescu, W. Strielkowski, M. Tvaronavičienè, Energies, 13 (9), 2280 (2020)

18. M. Liu, N. Tay, S. Bell, M. Belusko, R. Jacob, G. Will, W. Saman, F. Bruno, Renewable and Sustainable Energy Reviews, 53, 1411-1432 (2016)

19. M. Mahmoud, M. Ramadan, A. Olabi, K. Pullen, S. Naher, Energy Conversion and Management, 210, 112670 (2020)

20. A. Dahash, F. Ochs, M. Janetti, W. Streicher, Applied Energy, 239, 296-315 (2019)

21. D. Munoz-Rojas, X. Moya, Materials for Sustainable Energy Applications: Conversion, Storage, Transmission, and Consumption (2017)

22. O. Marchenko, S. Solomin, International Journal of Hydrogen Energy, 40 (10), 38013805 (2015)

23. W. Strielkowski, D. Streimikiene, A. Fomina, E. Semenova, Energies, 12 (24), 4790 (2019)

24. R. Ford, M. Pritoni, A. Sanguinetti, B. Karlin, Building and Environment, 123, 543-554 (2017)

25. C. Mahapatra, A. Moharana, V. Leung, Sensors, 17 (12), 2812 (2017) 
26. W. Strielkowski, E. Volkova, L. Pushkareva, D. Streimikiene, Energies, 12 (7), 1392 (2019)

27. F. Shirani, C. Groves, K. Henwood, N. Pidgeon, E. Roberts, Energy Policy, 144, 111637 (2020) 